(CC16) as a biomarker of acute or chronic pulmonary effects. Biomarkers 2007;12:445-67.

8. Jorens PG, Sibelle Y, Goilding NJ, et al. Potential role of Clara cell protein, an endogenous phospholipase A2 inhibitor, in acute lung injury. Eur Respir $J$ 1995;8:1647-53.

9. Vestbo J, Anderson W, Coxson HO, et al. Evaluation of COPD Longitudinally to Identify Predictive Surrogate Endpoints (ECLIPSE). Eur Respir J 2008;31:869-73.

10. Bernard A, Hermans C. Biomonitoring of early effects on the kidney or lung: the science of the total environment. Sci Total Environ 1997;199:205-11.

11. Agusti AG, Noguera A, Sauleda J, et al. Systemic effects of chronic obstructive pulmonary disease. Eur Respir J 2003:21:347-60.

12. de Torres JP, Cordoba-Lanus E, Lopez-Aguilar C, et al. C-reactive protein levels and clinically important predictive outcomes in stable COPD patients. Eur Respir J 2006;27:902-7.

13. Dev D, Wallace E, Sankaran R, et al. Value of Creactive protein measurements in exacerbations of chronic obstructive pulmonary disease. Respir Med 1998;92:664-7.

14. Dahl M, Vestbo J, Lange $P$, et al. C-reactive protein as a predictor of prognosis in chronic obstructive pulmonary disease. Am J Respir Crit Care Med 2007;175:250-5

15. Keatings VM, Collins PD, Scott DM, et al. Differences in interleukin-8 and tumor necrosis factoralpha in induced sputum from patients with chronic obstructive pulmonary disease or asthma. Am J Respir Crit Care Med 1996;153:530-4

16. Burrows BJ, Bloom JW, Traver GA, et al. The course and prognosis of different forms of chronic airway obstruction in a sample from the general population. N Engl J Med 1987:317:1309-14.

17. Schriver EE, Davidson JM, Sutcliffe MC, et al Comparison of elastin peptide concentrations in body fluids from healthy volunteers, smokers, and patients with chronic obstructive pulmonary disease. Am Rev Respir Dis 1992;145:762-6.

18. Stone JP, Glottlieb DJ, O'Connor GT, et al. Elastin and collagen degradation products in urine of smokers with and without chronic obstructive pulmonary disease. Am J Respir Crit Care Med 1995;151:952-9.

19. Ma S, Lin YY, Turino GM. Measurements of desmosine and isodesmosine by mass spectrometry in COPD. Chest 2007;131:1363-71.

20. Boschetto $\mathbf{P}$, Quintavalle $\mathrm{S}$, Zeni E, et al. Markers of emphysema are associated with more severe chronic obstructive pulmonary disease. Thorax

2006;61:1037-42.

21. Viglio S, Annovazzi L, Luisetti $M$, et al. Progress in the methodological strategies for the detection in real samples of desmosine and isodesmosine, two biological markers of elastin degradation. J Sep Sci 2007;30:202-13.

22. Cantor J0, Cerreta JM, Ochoa M, et al. Aerosolized hyaluronan limits airspace enlargement in a mouse model of cigarette smoke-induced pulmonary emphysema. Exp Lung Res 2005;31:417-30.

23. Ma S, Lin YY, Turino GM. The effect of tiotropium (TIO) on levels of desmosine and isodesmosine (D/I) in urine, plasma, and sputum in COPD (abstract). Eur Respir J 2007;30(Suppl 51):355s.

24. Parr DG, White AJ, Bayley DL, et al. Inflammation in sputum relates to progression of disease in subjects with COPD: a prospective descriptive study. Respir Res 2006; 7:136.

25. Donaldson GC, Seemungal TAR, Patel IS, et al. Airway and systemic inflammation and decline in lung function in patients with COPD. Chest 2005; 128:1995-2004.

26. Fogarty A, Jones S, Britton JR, et al. Systemic inflammation and decline in lung function in a general population: a prospective study. Thorax 2007;62:515-20.

27. American Thoracic Society/European Respiratory Society. Standards for the diagnosis and management of individuals with alpha-1antitrypsin deficiency. Am J Respir Crit Care Med 2003;168:818-900.

28. DeMeo DL, Sandhaus RA, Barker AF, et al. Determinants of airflow obstruction in severe alpha-1antitrypsin deficiency. Thorax 2007;62:806-13.

29. DeMeo DL, Campbell EJ, Barker AF, et al. IL10 polymorphisms are associated with airflow obstruction in severe alpha1-antitrypsin deficiency. Am J Respir Cell Mol Biol 2008;38:114-20.

\title{
RAGE: a biomarker for acute lung injury
}

\section{Mark J D Griffiths, ${ }^{1,2,3}$ Danny F McAuley ${ }^{3,4,5}$}

Acute lung injury (ALI), and its more severe counterpart the acute respiratory distress syndrome (ARDS), are syndromes of acute respiratory failure associated with pulmonary oedema caused by increased permeability of the alveolar-capillary membrane. Many clinical scenarios are recognised as being associated with a high incidence of ALI, including the archetypal direct pulmonary and blood borne insults of pneumonia and severe sepsis, respectively. The internationally accepted diagnostic criteria ${ }^{1}$ are non-specific to the point of including patients with relatively mild hypoxia and patients with lung pathology that may be different from the classical diffuse alveolar damage. ${ }^{2}$ ALI is not uncommon but it is challenging to study, partly because the patients are heterogenous in the causes and severity of their illness. Furthermore,

\footnotetext{
${ }^{1}$ Royal Brompton Hospital, AICU, London, UK; ${ }^{2}$ Unit of Critical Care, National Heart and Lung Institute, Imperial College London, London, UK; ${ }^{3} \mathrm{UK}$ and Eire Acute Lung Injury Research Group; ${ }^{4}$ Northern Ireland Regional Intensive Care Unit, Royal Victoria Hospital, Belfast, UK; ${ }^{5}$ Respiratory Medicine Research Group, The Queen's University of Belfast, Belfast, UK

Correspondence to: Dr Mark Griffiths, Unit of Critical Care, Royal Brompton Hospital, Sydney Street, London SW3 6NP, UK; m.griffiths@imperial.ac.uk
}

patients die with rather than from respiratory failure in the majority of cases. ${ }^{3}$ These issues partly account for the fact that only one intervention has been shown to affect the survival of patients with ALI. The National Heart, Lung and Blood Institute (NHLBI) ARDS Network ARMA study, ${ }^{4}$ arguably the most important trial in respiratory medicine in the last 20 years, demonstrated an approximately $10 \%$ survival advantage in favour of a ventilation strategy that limited tidal volume $(6 \mathrm{ml} / \mathrm{kg}$ predicted body weight) and plateau pressure $(\leqslant 30$ $\mathrm{cm} \mathrm{H}_{2} \mathrm{O}$ ) compared with "standard" ventilatory parameters $(12 \mathrm{ml} / \mathrm{kg}$ and $\leqslant 50$ $\mathrm{cm} \mathrm{H}_{2} \mathrm{O}$ ).

A biomarker is a clinical parameter that is measured with a view to providing information about a disease process, in this case ALI (box 1). Apart from informing the diagnostic process, biomarkers might be used to predict which patients at risk of ALI develop severe ARDS, which of these will develop pulmonary fibrosis requiring prolonged ventilatory support ${ }^{5}$ and ultimately who dies. Soluble receptor of advanced glycation end-products (RAGE), the cleaved form of the receptor, measured in plasma has been proposed as a biomarker of type I alveolar cell injury. Plasma RAGE concentrations were elevated in samples from patients with ALI compared with healthy controls and patients with hydrostatic oedema. ${ }^{6}$ In this issue of Thorax, Calfee and colleagues ${ }^{7}$ from the NHLBI ARDS Network report the results of measuring soluble RAGE levels in plasma samples from 676 patients enrolled in the ARMA study, both at entry to the study and after 3 days of standard or protective ventilation (see page 1083). At entry, higher RAGE levels were associated with higher radiographic and physiological indices of ALI severity as well as the nonpulmonary Acute Physiology and Chronic Health Evaluation (APACHE 3) score.? These data suggest that RAGE may be a marker of disease severity but the potential predictive value of a raised plasma RAGE level needs to be tested in patients at risk of developing ALI in a prospective longitudinal study. Furthermore, in the group randomised to the "standard" mechanical ventilation but not the protective ventilation group, higher baseline RAGE was associated with increased mortality and fewer ventilator-free and organ failure-free days. Because ventilation using $6 \mathrm{ml} / \mathrm{kg}$ predicted body weight has become a standard of care, ${ }^{8}$ this observation casts a shadow over the potential usefulness of RAGE although, as the authors state, such subgroup analyses should be viewed with caution.

In both groups plasma RAGE levels decreased 3 days after enrolment, but had fallen by $15 \%$ more in the protective ventilation group. Does this mean that RAGE joins the list of potential biomarkers of ventilator associated lung injury? ${ }^{9}$ The 
Box 1 Properties of an ideal biomarker for acute lung injury and the acute respiratory distress syndrome

Modified from Bucher and colleagues. ${ }^{27}$

- Has biological plausibility in terms of its role in the pathogenesis of disease

- Associated with a clinically important outcome such as mortality

- Modified by an effective intervention to change the target outcome of interest

- Measurement is safely, easily and reproducibly carried out in the critically ill

answer is possibly. Why would such a biomarker be so valuable? It is accepted that a low tidal volume and low airway pressure mechanical ventilation strategy confers a survival advantage and it seems likely that there is no safe threshold for these parameters. ${ }^{10}$ In contrast, the best efforts to characterise the effects of other ventilatory parameters, for example the optimum level of positive end-expiratory pressure, ${ }^{11-13}$ on the survival of patients with ALI have yielded inconclusive and for the most part negative results. An ideal biomarker of ventilator associated lung injury could, therefore, be used as a surrogate outcome measure in clinical studies and could guide ventilation strategy in individual patients. To be clinically useful, a biomarker would need to change significantly within hours rather than days of a change in a ventilatory parameter. Secondly, the biomarker should be specifically affected by ventilator associated lung injury, rather than its downstream consequences that can be affected by other variables, such as systemic inflammation and dysfunction of other organs. ${ }^{14}$ Circulating RAGE levels respond rapidly after lung injury: in an animal model of ALI induced by intratracheal hydrochloric acid, RAGE was elevated in bronchoalveolar lavage fluid and to a lesser extent serum only $2 \mathrm{~h}$ after injury. ${ }^{6}$ Secondly, RAGE is highly expressed in the lung compared with other organs and particularly on alveolar type I epithelial ${ }^{15}$ and endothelial cells ${ }^{16}$ and so the release of RAGE in the lung may follow alveolar epithelial and endothelial injury. Alternatively, it may occur as part of a pulmonary inflammatory response. Whatever the initiating stimulus, the movement of soluble RAGE into the systemic circulation may be enhanced by increased permeability of the alveolar-capillary membrane. While all of these processes are thought to be mediated by ventilator associated lung injury, none is specific for this mechanism of injury. ${ }^{17}$
Soluble RAGE shows considerable promise as a biomarker in ALI but is it just an epiphenomenon or do RAGE and its ligands contribute to the pathogenesis of ALI? RAGE is a member of the immunoglobulin superfamily whose ligands include advanced glycation end-product modified proteins, $\beta$-amyloid, S100A12 (also known as calgranulin $\mathrm{C}$ and EN-RAGE) and high mobility group box-1 (HMGB-1 or amphoterin).$^{18}$ Ligand binding to the intact receptor activates signalling pathways, including nuclear factor $\mathrm{\kappa B}$, leading to induction of inflammatory cytokines, proteases and oxidative stress. ${ }^{19} 20$ When RAGE induced effects were suppressed by a neutralising antibody, survival in a mouse model of sepsis was improved ${ }^{21}$ and inflammation in models of diabetes and chronic joint inflammation was reduced. Similarly, both HMGB-1 and S100A12 have been implicated in the overwhelming inflammatory response that characterises $\mathrm{ALI}^{22}$ but the contribution of RAGE activation to alveolar inflammation in ALI is not well understood. However, recent data suggest that in a murine model of lipopolysaccharide induced lung injury, exogenous soluble RAGE reduced the inflammatory response, perhaps acting as a decoy receptor. ${ }^{23}$ Hence increased soluble RAGE in a tissue compartment may actually reflect an anti-inflammatory response rather than a consequence of parenchymal lung injury, which suggests that an elevated soluble RAGE level would predict a favourable outcome from ALI.

Finally, RAGE expression is depressed in the lungs of patients with established idiopathic pulmonary fibrosis and those of mice treated with bleomycin, which induces a fibrosing alveolitis. ${ }^{24}{ }^{25}$ An antifibrotic role for RAGE has been inferred from experimental models of fibrosing alveolitis in knockout mice lacking membrane RAGE. ${ }^{25} 26$

The ARDS Network investigators have again used their unrivalled source of study material to produce more thought provoking insights into a means of improving the management of patients with ALI. Measurement of soluble RAGE in plasma joins an increasing list of candidate biomarkers of important processes that constitute ALI. It remains to be seen whether a single marker or a panel of markers will emerge to become robust outcomes for studies or useful tools in the management of individual patients.

Competing interests: None.

Thorax 2008:63:1034-1036. doi:10.1136/thx.2008.101493

\section{REFERENCES}

1. Slutsky AS. Mechanical ventilation. American College of Chest Physicians' Consensus Conference. Chest 1993;104:1833-59.

2. Griffiths MJD, Evans TW. Acute respiratory distress syndrome. In: Gibson GJ, Geddes DM, Costabel U, Sterk PJ, Corrin B, eds. Respiratory medicine, 3rd Edn. London: Saunders, 2003:736-63.

3. Montgomery AB, Stager MA, Carrico CJ, et al. Causes of mortality in patients with the adult respiratory distress syndrome. Am Rev Respir Dis 1985;132:485-9.

4. The Acute Respiratory Distress Syndrome Network. Ventilation with lower tidal volumes as compared with traditional tidal volumes for acute lung injury and the acute respiratory distress syndrome. N Engl J Med 2000;342:1301-8.

5. Martin C, Papazian L, Payan MJ, et al. Pulmonary fibrosis correlates with outcome in adult respiratory distress syndrome. A study in mechanically ventilated patients. Chest 1995;107:196-200.

6. Uchida T, Shirasawa M, Ware LB, et al. Receptor for advanced glycation end-products is a marker of type I cell injury in acute lung injury. Am J Respir Crit Care Med 2006;173:1008-15.

7. Calfee CS, Ware LB, Eisner MD, et al. Plasma receptor for advanced glycation end-products and clinical outcomes in acute lung injury. Thorax 2008;63:1083-9.

8. Wheeler AP, Bernard GR. Acute lung injury and the acute respiratory distress syndrome: a clinical review. Lancet 2007;369:1553-64.

9. Frank JA, Parsons PE, Matthay MA. Pathogenetic significance of biological markers of ventilatorassociated lung injury in experimental and clinical studies. Chest 2006;130:1906-14.

10. Hager DN, Krishnan JA, Hayden DL, et al. Tidal volume reduction in patients with acute lung injury when plateau pressures are not high. Am J Respir Crit Care Med 2005;172:1241-5.

11. Mercat A, Richard JC, Vielle B, et al. Positive endexpiratory pressure setting in adults with acute lung injury and acute respiratory distress syndrome: a randomized controlled trial. JAMA 2008;299:646-55

12. Meade MO, Cook DJ, Guyatt GH, et al. Ventilation strategy using low tidal volumes, recruitment maneuvers, and high positive end-expiratory pressure for acute lung injury and acute respiratory distress syndrome: a randomized controlled trial. JAMA 2008;299:637-45.

13. Brower RG, Lanken PN, Maclntyre N, et al. Higher versus lower positive end-expiratory pressures in patients with the acute respiratory distress syndrome. N Engl J Med 2004;351:327-36.

14. Tremblay LN, Slutsky AS. Ventilator-induced injury: from barotrauma to biotrauma. Proc Assoc Am Physicians 1998;110:482-8

15. Dahlin KA, Mager EM, Allen L, et al. Identification of genes differentially expressed in rat alveolar type I cells. Am J Respir Cell Mol Biol 2004;31:309-16.

16. Brett J, Schmidt AM, Yan SD, et al. Survey of the distribution of a newly characterized receptor for advanced glycation end products in tissues. Am J Pathol 1993;143:1699-712.

17. Pinhu L, Whitehead T, Evans T, et al. Ventilatorassociated lung injury. Lancet 2003;361:332-40.

18. Donahue JE, Flaherty SL, Johanson CE, et al. RAGE, LRP-1, and amyloid-beta protein in Alzheimer's disease. Acta Neuropathol 2006;112:405-15.

19. Ghavami S, Rashedi I, Dattilo BM, et al. S100A8/A9 at low concentration promotes tumor cell growth via RAGE ligation and MAP kinase-dependent pathway. $J$ Leukoc Biol 2008;83:1484-92.

20. Aleshin A, Ananthakrishnan R, Li Q, et al. RAGE modulates myocardial injury consequent to LAD infarction via impact on JNK and STAT signaling in a murine model. Am J Physiol Heart Circ Physiol 2008;294:H1823-32.

21. Lutterloh EC, Opal SM, Pittman DD, et al. Inhibition of the RAGE products increases survival in experimental models of severe sepsis and systemic infection. Crit Care 2007;11:R122.

22. Wittkowski H, Sturrock A, van Zoelen MA, et al. Neutrophil-derived S100A12 in acute lung injury and 
respiratory distress syndrome. Crit Care Med 2007:35:1369-75.

23. Zhang H, Tasaka S, Shiraishi Y, et al. Role of soluble receptor for advanced glycation end-products on endotoxin-induced lung injury. Am J Respir Crit Care Med 2008;178:356-62.

24. Queisser MA, Kouri FM, Konigshoff M, et al. Loss of RAGE in pulmonary fibrosis: molecular relations to functional changes in pulmonary cell types. Am J Respir Cell Mol Biol 2008;39:337-45.

25. Englert JM, Hanford LE, Kaminski N, et al. A role for the receptor for advanced glycation end products in idiopathic pulmonary fibrosis. Am J Pathol 2008;172:583-91.

26. He M, Kubo H, Ishizawa K, et al. The role of the receptor for advanced glycation end-products in lung

\section{Thorax update: October 2007- September 2008}

\section{Jadwiga A Wedzicha, Sebastian L Johnston}

We have now completed our sixth year as Thorax editors and are delighted that the Journal has continued to be so successful. As usual, the annual round of impact factor announcements was eagerly awaited by the editorial team and we were all delighted with the news that our impact factor for 2007, published in June 2008, had risen to the highest ever for Thorax at 6.226. The impact factor for 2007 reflects the number of citations in 2007 divided by the number of original papers and reviews published in Thorax in 2005 and 2006. We have thus maintained our position as the second highest ranked respiratory journal in terms of impact factor, behind the American Journal of Respiratory and Critical Care Medicine. This increase in the Thorax impact factor is a result of the high quality papers and reviews that you have all submitted to the journal for publication.

Perhaps the most visible change has been (we hope!) the change of front cover and our successful introduction of images to illustrate each issue (figs 1-3). These images were selected by the COPD research team at UCL Medical School, according to some democratic process! As they have to be of high quality, they come from the Science Photo Library. In addition, the inside page format has changed, and this is consistent with the new house style of BMJ Journals.

The number of submissions over the past year has remained steady compared with previous years at 1434, with 872 full original papers submitted to the journal. The time to the first decision on an original paper that has been through a full peer review is now a median of 50 days, but this also includes statistical review for all potentially acceptable papers. Thorax has a policy of rejecting papers without review that will not do well in the peer review

Correspondence to: Professor J A Wedzicha, Thorax Editorial Office; j.a.wedzicha@medsch.ucl.ac.uk process or are outside the scope of the journal. This means that authors can rapidly submit their work to another journal for consideration. However, the large number of submissions-particularly for original papers - means that our acceptance rate for original research papers now stands at around 14\%, although for case reports and Images in Thorax the acceptance rate is lower. During the past year we have also received an increased number of letters for publication at 115 , and this has consisted of both correspondence about previously published papers and also research letters, all of which undergo peer review as for original papers.

We are grateful to all our reviewers who have taken time to review Thorax papers. The rigorous standard of peer review has helped to achieve the high quality of papers published in the journal. However, we have a significant number of review requests that are declined and sadly this figure is creeping up, with $37 \%$ of review requests declined over the past year.

Since the start of our editorship, we have always tried to ensure that there is something in Thorax each month of interest to all readers and thus educational features are important. The "Images in Thorax" series ${ }^{1}$ and the Lung Alerts, ${ }^{2}$ both published monthly, have proved very popular and the Alerts are serviced by our younger readers. In view of the large number of case reports submitted to the journal, we have decided to start a new feature called "Pulmonary Puzzles". "These "Puzzles" consist of two parts, one providing details of the case and the other the answer, published in a different place in the journal. Over the last year we have had 47 articles submitted as "Pulmonary Puzzles" and a total of 117 articles for the "Images in Thorax" section, emphasising the popularity of these educational features. fibrosis. Am J Physiol Lung Cell Mol Physiol 2007;293:L1427-36.

27. Bucher HC, Guyatt GH, Cook DJ, et al. Users' guides to the medical literature: XIX. Applying clinical trial results. A. How to use an article measuring the effect of an intervention on surrogate end points. EvidenceBased Medicine Working Group. JAMA 1999;282:771-8.

A highlight of the past year was the 25th anniversary of the British Thoracic Society (BTS) and, to celebrate this event, Thorax published seven articles by BTS members highlighting achievements in respiratory medicine and some of our aspirations for the future..$^{4-10}$ We also published a report on the BTS Winter meeting held in London in December 2007. ${ }^{11}$ A number of important guidelines and consensus statements have also been published, including the British guideline on asthma management, ${ }^{12}$ BTS statement on malignant mesothelioma, ${ }^{13}$ BTS criteria for specialist referral, admission, discharge and follow-up, ${ }^{14}$ guidelines on the management of cough in children, ${ }^{15}$ interstitial lung disease guideline ${ }^{16}$ and a consensus statement on pulmonary hypertension. ${ }^{17}$ We have published some excellent reviews during the past year; we have completed the series on exacerbations of cystic fibrosis ${ }^{18} 19$ and interstitial lung disease $\mathrm{e}^{20-24}$ and started an interesting series on obesity and the lung. ${ }^{25} 26$

During our editorship we have had a series of very productive annual meetings for the Associate Editors, the most recent of which was held in November 2007 in London. We were delighted to be joined by editors of both the British Medical Journal and the Lancet who gave us

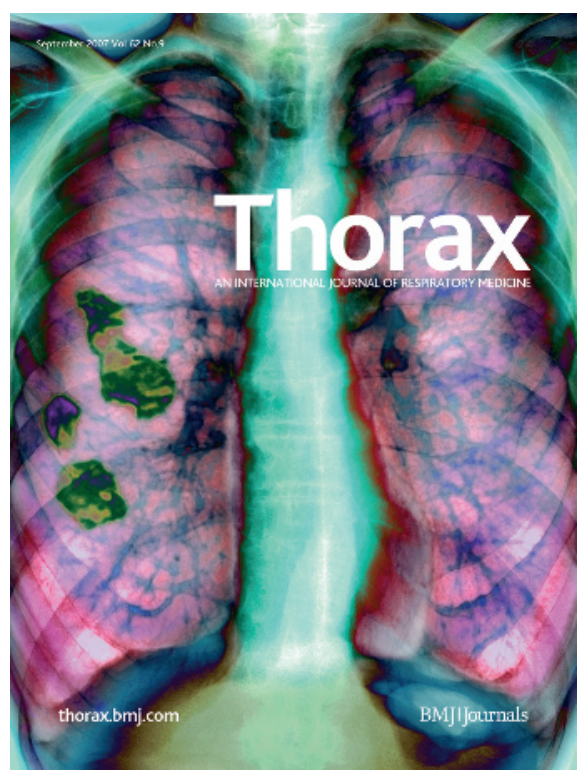

Figure 1 Thorax cover. 